\title{
Challenges in COVID-19 diagnosis
}

\author{
Erenler $\mathrm{AK}^{1}$, Baydin $\mathrm{A}^{2}$ \\ Hitit University, School of Medicine, Department of Emergency Medicine, Corum, Turkey. \\ akerenler@hotmail.com
}

\begin{abstract}
OBJECTIVE: In this narrative review, our aim was to clarify the roles of diagnostic methods used in COVID-19 disease.

BACKGROUND: Coronavirus disease 2019 (COVID-19) caused by coronavirusis emerged as the major healthcare challenge globally. The mainstay approach to limit this virus spread is an early and accurate diagnosis of the viral infection and appropriate quarantine of patients with coronavirus infection.

RESULTS: Real time polymerase chain reaction (PCR) offers a quick detection of the disease in either symptomatic or asymptomatic patients. In literature, there are numerous studies that underline the importance of CT as the first-step diagnostic tool in COVID-19 diagnosis. Even in asymptomatic patients, COVID-19 pneumonia may manifest with chest CT imaging abnormalities.

CONCLUSION: There is a need for an algorithm, which involves a combination of PCR and CT in diagnosis of COVID-19 (Ref. 85). Text in PDF www.elis.sk

KEY WORDS: COVID-19, polymerase chain reaction, computed tomography, diagnosis.
\end{abstract}

\section{Introduction}

In December 2019, a series of pneumonia cases of unknown origin were identified in Wuhan, China. Lately, the etiological agent was defined as the 2019 novel coronavirus (2019-nCoV), and the disease was recently declared by the World Health Organization (WHO) as coronavirus disease 2019 (COVID-19) (1). After epidemiological investigations carried out by the Wuhan Center for Disease Control and Prevention, it was understood that the patients worked at a local indoor seafood market. In this marketplace, besides fish and shellfish, hedgehogs, badgers, snakes, birds (turtledoves), animal carcasses and animal meat were available before the outbreak began (2).

According to WHO, Coronaviruses belong to the family Coronaviridae and the order Nidovarales, a family that includes viruses that cause diseases ranging from the common cold to severe acute respiratory syndrome (SARS) and the Middle East respiratory syndrome (MERS) (3). It is also known that Coronaviruses are enveloped non-segmented positive-sense RNA viruses broadly distributed in humans and other mammals (4).

Among its signs and symptoms, the most prominent ones are: fever, cough and shortness of breath. These symptoms may appear 2-14 days after an exposure (5). The disease has a high infectivity and is transmitted from person to person in hospital

${ }^{1}$ Hitit University, School of Medicine, Department of Emergency Medicine, Corum, Turkey, and ${ }^{2}$ Samsun Ondokuzmayis University, School of Medicine, Department of Emergency Medicine, Samsun, Turkey

Address for correspondence: A.K. Erenler, MD, Hitit Üniversitesi, Tip Fakültesi, Acil Tip Anabilim Dali, Çorum, Turkey.

Phone: +905324475563, Fax: 03642191938 and family settings (6). Limiting human-to-human transmission in order to reduce secondary infections among close contacts and healthcare workers is essential. Based on previous experience of management of MERS and SARS infections, the WHO also recommends avoiding close contact with people suffering from acute respiratory infections, frequent hand-washing especially after a direct contact with ill people or their environment, and avoiding unprotected contact with farm or wild animals. Moreover, people with symptoms of acute respiratory infection should practice cough etiquette, which is to maintain distance, cover coughs and sneezes with disposable tissues or clothing, and wash hands, and enhanced standard infection prevention and control practices are recommended in hospitals, especially in emergency departments (EDs) (7). In this review, we aimed to clarify and compare diagnostic values of CT and PCR in COVID-19.

\section{Materials and methods}

A systematic literature search of PubMed and Embase (Elsevier) databases was performed using the keywords "coronavirus", "nCoV", "computed tomography", "2019-nCoV" and "COVID-19". Furthermore, the WHO database of publications on novel coronavirus was screened for potentially relevant publications. One of the reviewers with an experience in database searches designed the search strategy, which was subsequently revised by other reviewers. With consideration to the date of the earliest confirmed reports of COVID-19, the searches were limited to articles published in 2019 and 2020. A total of 85 articles, reviews and case reports were involved into the study. If the full text of the article was not available and the researchers failed to retrieve it, then the article has been excluded if the abstracts were non-explanatory. 
Signs, symptoms and laboratory analyses

The most common symptoms in COVID-19 are related to respiratory system (8). The signs and symptoms of COVID-19 pneumonia are similar to other pneumonias (9). The majority of the patients with COVID-19 are admitted to EDs with mild, influenzalike symptoms. In older patients and those with co-morbidities, the disease may progress to interstitial pneumonia, acute respiratory distress syndrome (ARDS) and death. Death occurs in $2-5 \%$ of the patients (10).

Zhao et al found that angiotensin-converting enzyme 2 (ACE2) was the receptor of COVID-19. In normal lung tissue, ACE2 is mainly expressed by type I and type II alveolar epithelial cells. It was reported that $83 \%$ of alveolar cells expressed ACE2. Therefore, COVID-19 infection seems to show its effects by causing damage to most II type alveolar cells (11).

Extrapulmonary site for virus replication may be digestive system since a high concentration of viral RNA in anal swabs was determined (12). In a study, interestingly, $13.3 \%$ patients had diarrhoea, while no patients had dyspnoea (13).

When laboratory findings of the disease were investigated, white blood cell (WBC) count was usually normal or might be decreased. Besides, lymphocyte count might decrease and hypersensitive $\mathrm{C}$ reactive protein (CRP) might be increased. In the study, it was reported that serum lactate dehydrogenase (LDH) was significantly increased, while albumin was decreased. Alanine aminotransferase (ALT), aspartate aminotransferase (AST), total bilirubin (Tbil), serum creatinine (Scr) and other items showed no significant changes $(8,14-16)$.

In the study with 85 patients; fever, cough and expectoration were found to be the most common symptoms, 14 patients had a decreased oxygen saturation, 33 had leukopenia, 53 had lymphopenia, and 82 had elevated CRP (17).

It was also reported that the CRP, erythrocyte sedimentation rate and LDH showed a significantly positive correlation with the severity of COVID-19 pneumonia (18). Additionally, an increased expression of IL-2R and IL-6 in serum was shown to be related to the severity of the COVID-19 pneumonia and the prognosis of the patients (8).

Even though the most common symptom was fever, body temperature screening might not be an adequate screening as it can potentially miss travellers incubating the disease or travellers concealing fever during travel and might contribute to the importation of the virus to the countries of destination since patients having the virus in incubation period of the disease might be missed. Therefore, travel restrictions and 14-day quarantine of people who visited areas with a high risk are recommended to prevent spreading of the disease $(15,19)$. In the study, the median time from exposure to onset of illness was found to be 4 days (20). Patients might also be totally non-symptomatic (21). The virus may transmit from human to human even in non-symptomatic phase and during incubation by patients with brief and non-specific illness. The severity of the disease is known to be milder in children and more likely to infect elderly people with chronic comorbidities $(22,23)$. There is a lack of evidence about transmission to neonates during labour (4).

\section{PCR testing in COVID-19}

In such pandemics that we experience, it is essential to reduce anxiety through a rapid diagnosis in order to improve decision making and crisis management (25). Real time PCR is accepted to be a reliable and quick test in detecting both symptomatic and asymptomatic patients $(19,23,26)$. It is obtained from swabs, sputum, secretions from the lower respiratory tract, or blood (27). As an advantage, laboratory-developed tests can be adapted for fully automated PCR platforms (28).

However, a negative Real Time PCR test result does not completely rule out COVID-19. It is not rational to use it as a single factor for the management of patients. Experiences indicate that re-testing should be considered in consultation with public health authorities $(29,30)$. This method also has some disadvantages since it is time-consuming, expensive and it depends upon technical expertise. It is dangerous since the virus must be contained. Also, the presence of viral RNA or DNA does not always reflect an acute disease and contribution of positive PCR results to disease severity is not always explicitly exhibited (31).

The success of this method depends on the presence of viral genome in sufficient amounts at the site of the sample collection that can be amplified (32). For high quality nasopharyngeal specimen collection procedure, the swab must be inserted into the nostril parallel to the palate. The swab must be maintained in place for a few seconds in order to enable secretion absorption and then, the swab must be quickly placed in a sterile tube, containing $2-3 \mathrm{~mL}$ of viral transport media. The procedure for collecting oropharyngeal (e.g. throat) specimens entails swabbing the posterior pharynx, avoiding the tongue, and immediate placement of the swab into another separate sterile tube, also containing $2-3 \mathrm{~mL}$ of viral transport media (23).

Since viral pneumonias may not be identified in the production of purulent sputum, a nasopharyngeal swab is usually the collection method used to obtain a specimen for testing. Besides, nasopharyngeal specimens, either, may miss some infections. When a deeper specimen is needed, bronchoscopy might be necessary (33). During sampling, professionals must wear personal protective clothing including eye protection (goggles), a filtering facepiece respirator (N95), a surgical cap, gloves, a fluid-resistant gown, and shoe covers (34).

The nasopharyngeal swabs using the real-time PCR method, besides coronavirus, rhinovirus and influenza might also be isolated (35).

As was done in Singapore, in order to win the war in pandemics, it seems vital to increase the number of tests of all suspected individuals and enhanced the surveillance for all the patients with pneumonia and a tracing of contacts of the confirmed cases within their clusters (36).

\section{Chest computed tomography findings in COVID-19}

In typical COVID-19 pneumonia cases, single or multiple patchy ground glass shadows accompanied by a septal thickening are common. As the disease progresses, the lesion grows, and the ground glass shadow coexists with the solid shadow or the stripe shadow (8). Unenhanced chest CT findings reveal multiple 
bilateral and peripheral ground-glass opacities (GGOs) in the superior segments of both lower, peripheral lobes without sparing the subpleural regions (37-51).

It was reported that GGOs might be seen in the central area of the lung lobe as round nodular-like lesions, which is different from the common imaging manifestations that are patchy-like lesion in subpleural region in the early stage of the disease (52). It was also reported that $\mathrm{CT}$ findings might include bilateral pleural effusions (21). Patchy consolidation and ground-glass opacities observed in chest CT may be distributed along the bronchial bundles or subpleural regions in both lungs (53).

In patients with COVID-19 pneumonia, early-stage lung CT scans mostly show multiple, small patch-like shadows, and interstitial changes, which were more obvious in the extrapulmonary region. These shadows subsequently progressed to multiple ground-glass opacities in both lungs, along with infiltration shadows with a "large white lung" observed in more severe cases. (54).

In the study by $\mathrm{Wu} \mathrm{J}$ et al, it was reported that the majority of the lesions were multiple and were detected in subpleural region bilaterally. Single GGOs and a combination of GGOs and consolidation were the most common lesions. Pleural parallel sign, intralobular septal thickening, halo sign, reversed-halo sign, pleural effusion and pneumatocele were also determined (55).

Pan F et al classified the abnormalities in chest $\mathrm{CT}$ in 4 categories as follows: Early stage (0-4 days after onset of the initial symptom): In this stage, GGO distributed subpleurally in the lower lobes unilaterally or bilaterally. Progressive stage (5-8 days after the onset of the initial symptom): In this stage, the infection rapidly aggravates and extends to a bilateral multi-lobe distribution with a diffuse GGO, crazy-paving pattern and consolidation. Peak stage (9-13 days after the onset of the initial symptom): In this stage, the involved area of the lungs slowly increase to the peak involvement and dense consolidation became more prevalent. The findings included a diffuse GGO, crazy-paving pattern, consolidation and residual parenchymal bands. Absorption stage ( $\geq 14$ days after the onset of the initial symptom): GGOs may be observed due to consolidation absorption. Crazy-paving pattern is not observed (56). Even in asymptomatic patients, COVID-19 pneumonia may manifest with chest CT imaging abnormalities (38).

There are also some atypical presentations seen in chest CT in COVID-19 pneumonia patients. Consolidative opacities superimposed on GGO may be found in a small number of cases, mainly in the elderly population. In the later stages of the disease, septal thickening, bronchiectasis, pleural thickening, and subpleural involvement might be seen. Pleural effusion, pericardial effusion, lymphadenopathy, cavitation, CT halo sign, and pneumothorax are uncommon, but may be seen with a disease progression (16, $49,57)$. Also, airway changes, pleural changes, fibrosis, nodules, etc., were demonstrated in COVID-19 patients (58). In the report, pneumothorax was also observed (59).

Pneumonia related to COVID-19 more likely affects multiple lobes and the size of the lesions vary from $1 \mathrm{~cm}$ to more than 3 $\mathrm{cm}(16,60)$.

It is also suggested to perform repetitive chest CTs in order to determine the prognosis of the disease. It is known that GGOs may evolve to consolidation as the disease progresses $(58,61,62)$. On the follow-up CTs, progressive opacifications, consolidation, interstitial thickening, fibrous strips and air bronchograms may be found compared to initial CT (18).

In the intermediate stage of the disease, an increase in the number and size of GGOs and progressive transformation of GGOs into multifocal consolidative opacities, septal thickening, and development of a crazy paving pattern might be observed. After about 2 weeks, consolidative opacities gradually resolve and the number of lesions and involved lobes decrease (57).

In the follow-up CT scan, the pulmonary vessels enlargement in areas, where new lung infiltrates develop, can be an early radiological sign of lung impairment (63). In the case report, CT showed fibrous lesions after a recovery (64). Small amounts of patchy ground-glass opacities and fibrous stripes in bilateral lungs may also persist (41).

As seen in SARS and MERS pneumonias, CT is recommended in COVID-19 for follow-up in individuals, who are recovering from COVID-19 to evaluate the long-term or permanent lung damage including fibrosis (65).

\section{Role of computed tomography in COVID-19 pneumonia}

Timely diagnosis of COVID-19 pneumonia is the mainstay of rapid management and treatment of the disease. Definitive diagnosis of the disease is based on PCR test, however, radiological findings have indispensable value in diagnosis. Given the fact that the most frequent imaging finding is GGO, careful interpretation of the chest radiographs is needed as GGOs may look very faint. CT scans are recommended in patients with suspicious lung abnormality $(44,53,66,67)$. However, it must be kept in mind that even though CT provide an early diagnosis and stratification of the disease, it may be totally normal in some patients (68).

In the study with 80 patients, 55 (68.75\%) showed abnormal chest CT images (69). In another study, $56 \%$ of early patients had a normal CT. It was concluded that chest CT had a limited sensitivity and negative predictive value early after symptom onset. CT imaging cannot be used as a reliable standalone tool to rule out COVID-19 infection (70). Chung et al revealed that $14 \%$ of the patients with COVID -19 had entirely normal chest CT examinations at presentation without GGOs or consolidation (71). In the study, two of 5 children with confirmed COVID-19 infection had no sign of abnormality at chest CT (72). CT abnormality was not determined in $17.9 \%$ with non-severe disease and in $2.9 \%$ with severe disease (67). In another study with 15 patients, the first nasal or pharyngeal swab samples in all 15 cases were positive, while 6 patients had no lesions in CT (73). In the report, 8 of 101 patients with COVID-19 had no abnormal findings in CT (50). Wei Xia et al reported that normal CT findings in COVID-19 was $20 \%$ (74). Another report revealed that 9 mild patients among 50 patients were negative in CT imaging (15). Among 149 PCR positive patients, 17 patients had normal CT at the time of admission (17).

The evidence revealed that a normal chest CT scan does not exclude the diagnosis of 2019-nCoV infection (75).

Another disadvantage of CT use as a sole diagnostic tool in COVID-19 pneumonia is that the CT manifestations of COVID-19 
pneumonia are similar to those of SARS, which are usually fast changing, multiple, and migratory, but the distribution of lesions is mainly in the middle and peripheral zones of the lung $(1,8,76)$. Similarities can be found in pneumonias related to MERS, H7N9 pneumonia, H1N1 virus infection, SARS, coronavirus infection, and avian influenza A (H5N1) $(64,71,77)$. The CT findings of COVID-19 also overlaps with the CT findings of adenovirus infection (78). This fact can be problematic in paediatric patients since coinfection is common in this group (74).

\section{Chest computed tomography vs PCR tests}

There is an ongoing debate on the diagnostic role of chest CT in COVID-19 pneumonia. Chest CT has a high sensitivity for diagnosis of COVID-19. Even though there are studies suggesting chest $\mathrm{CT}$ as the primary tool for the current COVID-19 detection in epidemic areas $(8,79,80)$, nucleic acid tests are recommended for a prompt diagnosis and treatment $(12,64,81)$.

However, the positive ratio of PCR detection for COVID-19 may be only $47.4 \%$ in the suspect patients, according to the study (82). Additionally, in the report, five out of 167 patients, whose PCR tests were negative, were diagnosed as COVID-19 pneumonia according to chest $\mathrm{CT}$ findings (83). While the rate of positivity in chest CT was found to be $88 \%$, the rate of positivity in PCR was found to be $59 \%$ of the patients (23). This result may be associated with similar CT findings observed in other viral pneumonias, but it is difficult to rely on nucleic acid detection alone (84). It was also reported that follow-up chest CTs improve earlier that RTPCT results turns negative (79). This finding emphasizes the role of chest CT in determining a disease progression. Dasheng et al. recommends $\mathrm{CT}$ as the first and immediate reference for doctors to screen the highly suspected cases and to take necessary actions while PCR serves as a confirmation tool, the results of which could be utilized later to decide (85). Nevertheless, a combination of CT imaging and nucleic acid tests is more likely to have a superior diagnostic value, when compared to each parameter alone (84).

\section{Conclusion}

PCR testing for COVID-19 diagnosis has some disadvantages: it relies on the presence of adequate viral genome in the sample site, probability of missing the period of viral replication and incorrect sampling method (32). CT imaging, as an alternative, also has some disadvantages. The radiation exposure and a weak diagnostic value, when the infection is limited to upper respiratory system or performed in the early stage, can be given as examples. Also, CT is problematic in differential diagnosis of various viral pneumonias. In conclusion, an algorithm, which involves a combination of PCR and CT must be determined in order to maintain an accurate and timely diagnosis of COVID-19.

\section{References}

1. Sun Z. Diagnostic Value of Chest CT in Coronavirus Disease 2019 (COVID-19). Curr Med Imaging 2020. DOI: 10.2174/15734056169992 00320163751.
2. Wu F, Zhao S, Yu B et al. A new coronavirus associated with human respiratory disease in China. Nature 2020; 579 (7798): 265-269. DOI: 10.1038/s41586-020-2008-3.

3. WHO Website. Available at: Novel Coronavirus (2019-nCoV). World Health Organization. https://www. who.int/emergencies/diseases/novelCoronavirus-2019. Published January 7, 2020.

4. Richman DD, Whitley RJ, Hayden FG et al. Clinical virology. 4th ed. Washington, DC: ASM Press, 2016.

5. CDC Website. Available at: https://www.cdc.gov/coronavirus/2019ncov/symptoms-testing/symptoms.html

6. Chan JF, Yuan S, Kok KH et al. A familial cluster of pneumonia associated with the 2019 novel coronavirus indicating person-to-person transmission: a study of a family cluster. Lancet 2020; 395 (10223): 514-523. DOI: 10.1016/S0140-6736 (20)30154-9.

7. Lai CC, Shih TP, Ko WC et al. Severe acute respiratory syndrome coronavirus 2 (SARS-CoV-2) and coronavirus disease-2019 (COVID-19): The epidemic and the challenges. Int J Antimicrob Agents 2020; 55 (3): 105924. DOI: 10.1016/j.ijantimicag.2020.105924.

8. Chen L, Liu HG, Liu W et al. Analysis of clinical features of 29 patients with 2019 novel coronavirus pneumonia. Zhonghua Jie He He Hu Xi Za Zhi 2020; 43 (3): 203-208. DOI: 10.3760/cma.j.issn.1001-0939.2020.03.013.

9. Zhao D, Yao F, Wang L et al. A comparative study on the clinical features of COVID-19 pneumonia to other pneumonias. Clin Infect Dis 2020. pii: ciaa247. DOI: 10.1093/cid/ciaa247.

10. World Health Organization. Coronavirus disease 2019 (COVID-19) Situation Report - 48. https://www.who.int/emergencies/ diseases/novelcoronavirus-2019/situation-reports/.

11. Zhao Y, Zhao Z, Wang Y et al. Single-cell RNA expression profiling of ACE2, the putative receptor of Wuhan 2019-nCov. bioRxiv 2020. https:// doi.org/10.1101/2020.01.26.919985.

12. Chen W, Lan Y, Yuan X et al. Detectable 2019-nCoV viral RNA in blood is a strong indicator for the further clinical severity. Emerg Microbes Infect 2020; 9 (1): 469-473. DOI: 10.1080/22221751.2020.1732837.

13. Dai WC, Zhang HW, Yu J et al. CT Imaging and Differential Diagnosis of COVID-19. Can Assoc Radiol J 2020; 71 (2): 195-200. DOI: 10.1177/0846537120913033.

14. Shi H, Han X, Zheng C. Evolution of CT Manifestations in a Patient Recovered from 2019 Novel Coronavirus (2019-nCoV) Pneumonia in Wuhan, China. Radiology 2020; 295 (1): 20. DOI: 10.1148/radiol.2020200269.

15. Xu YH, Dong JH, An WM et al. Clinical and computed tomographic imaging features of novel coronavirus pneumonia caused by SARS-CoV-2. J Infect 2020; 80 (4): 394-400. DOI: 10.1016/j.jinf.2020.02.017.

16. Han R, Huang L, Jiang $\mathbf{H}$ et al. Early Clinical and CT Manifestations of Coronavirus Disease 2019 (COVID-19) Pneumonia. Am J Roentgenol 2020: 1-6. DOI: 10.2214/AJR.20.22961.

17. Yang W, Cao Q, Qin L et al. Clinical characteristics and imaging manifestations of the 2019 novel coronavirus disease (COVID-19): A multi-center study in Wenzhou city, Zhejiang, China. J Infect 2020; 80 (4): 388-393. DOI: 10.1016/j.jinf.2020.02.016.

18. Xiong Y, Sun D, Liu Y et al. Clinical and High-Resolution CT Features of the COVID-19 Infection: Comparison of the Initial and Followup Changes. Invest Radiol 2020. DOI: 10.1097/RLI.0000000000000674.

19. Bwire GM, Paulo LS. Coronavirus disease-2019: is fever an adequate screening for the returning travelers? Trop Med Health 2020; 48: 14. DOI: 10.1186/s41182-020-00201-2. 
20. Xu XW, Wu XX, Jiang XG et al. Clinical findings in a group of patients infected with the 2019 novel coronavirus (SARS-Cov-2) outside of Wuhan, China: retrospective case series. BMJ 2020; 368: m606. DOI: 10.1136/bmj.m606.

21. Lin C, Ding Y, Xie B et al. Asymptomatic novel coronavirus pneumonia patient outside Wuhan: The value of CT images in the course of the disease. Clin Imaging 2020; 63: 7-9. DOI: 10.1016/j.clinimag.2020.02.008.

22. Yuan M, Yin W, Tao Z, Tan W, Hu Y. Association of radiologic findings with mortality of patients infected with 2019 novel coronavirus in Wuhan, China. PLoS One 2020; 15 (3): e0230548. DOI: 10.1371/journal. pone. 0230548 .

23. Lippi G, Simundic AM, Plebani M. Potential preanalytical and analytical vulnerabilities in the laboratory diagnosis of coronavirus disease 2019 (COVID-19) [published online ahead of print, 2020 Mar 16]. Clin Chem Lab Med 2020; /j/cclm.ahead-of-print/cclm-2020-0285/cclm-2020-0285. xml. DOI: $10.1515 / \mathrm{cclm}-2020-0285$.

24. Chen R, Chen J, Meng QT. Chest computed tomography images of early coronavirus disease (COVID-19) [published online ahead of print, 2020 Mar 11]. Can J Anaesth 2020; 1-2. DOI: 10.1007/s12630-020-01625-4.

25. Lagier JC, Colson P, Tissot Dupont $\mathbf{H}$ et al. Testing the repatriated for SARS-Cov2: Should laboratory-based quarantine replace traditional quarantine? [published online ahead of print, 2020 Mar 14]. Travel Med Infect Dis 2020; 101624. DOI: 10.1016/j.tmaid.2020.101624.

26. Liu R, Han H, Liu F et al. Positive rate of RT-PCR detection of SARSCoV-2 infection in 4880 cases from one hospital in Wuhan, China, from Jan to Feb 2020. Clin Chim Acta 2020; 505: 172-175. DOI: 10.1016/j. cca.2020.03.009.

27. Fang X, Zhao M, Li S, Yang L, Wu B. Changes of CT findings in a 2019 novel coronavirus (2019-nCoV) pneumonia patient. QJM 2020; 113 (4): 271-272. DOI: 10.1093/qjmed/hcaa038.

28. Pfefferle S, Reucher S, Nörz D, Lütgehetmann M. Evaluation of a quantitative RT-PCR assay for the detection of the emerging coronavirus SARS-CoV-2 using a high throughput system. Euro Surveill 2020; 25 (9): 2000152. DOI: 10.2807/1560-7917.ES.2020.25.9.2000152.

29. Food and Drug Administration. New York SARS-CoV-2 Real-time RT-PCR Diagnostic Panel - February 29, 2020. https:// www.fda.gov/media/135662/download. Last accessed, March 9, 2020

30. Xie X, Zhong Z, Zhao W, Zheng C, Wang F, Liu J. Chest CT for Typical 2019-nCoV Pneumonia: Relationship to Negative RT-PCR Testing [published online ahead of print, 2020 Feb 12]. Radiology 2020; 200343. DOI: 10.1148/radiol.2020200343.

31. Nguyen T, Duong Bang D, Wolff A. 2019 Novel Coronavirus Disease (COVID-19): Paving the Road for Rapid Detection and Point-of-Care Diagnostics. Micromachines (Basel) 2020; 11: 306. DOI: 10.3390/mi11030306.

32. Guo L, Ren L, Yang $S$ et al. Profiling Early Humoral Response to Diagnose Novel Coronavirus Disease (COVID-19). Clin Infect Dis 2020; ciaa310. DOI: $10.1093 /$ cid/ciaa310.

33. Loeffelholz MJ, Tang YW. Laboratory diagnosis of emerging human coronavirus infections - the state of the art. Emerg Microbes Infect 2020; 9 (1): 747-756. DOI: 10.1080/22221751.2020.1745095.

34. Nakajima K, Kato H, Yamashiro T et al. COVID-19 pneumonia: infection control protocol inside computed tomography suites. Jpn J Radiol 2020; 38: 391-393. DOI: 10.1007/s11604-020-00948-y.

35. Yormaz B, Findik D, Süerdem M. Differences of viral panel positive versus negative by real-time PCR in COPD exacerbated patients. Tuberk Toraks 2019; 67 (2): 124-130. DOI: 10.5578/tt.68471.
36. Tan SS, Yan B, Saw S et al. Practical laboratory considerations amidst the COVID-19 outbreak: early experience from Singapore. J Clin Pathol 2020; jclinpath-2020-206563. DOI: 10.1136/jclinpath-2020-206563.

37. Duan YN, Qin J. Pre- and Posttreatment Chest CT Findings: 2019 Novel Coronavirus (2019-nCoV) Pneumonia. Radiology 2020; 295: 21. DOI: $10.1148 /$ radiol.2020200323.

38. Shi H, Han $\mathbf{X}$, Jiang $\mathbf{N}$ et al. Radiological findings from 81 patients with COVID-19 pneumonia in Wuhan, China: a descriptive study. Lancet Infect Dis 2020; 20: 425-434. DOI: 10.1016/S14733099 (20)30086-4.

39. Huang C, Wang Y, Li X et al. Clinical features of patients infected with 2019 novel coronavirus in Wuhan, China. Lancet 2020; 395: 497-506. DOI: 10.1016/S0140-6736 (20)30183-5.

40. Lei J, Li J, Li X, Qi X. CT Imaging of the 2019 Novel Coronavirus (2019-nCoV) Pneumonia. Radiology 2020; 295: 18. DOI: 10.1148/ radiol.2020200236

41. Sun Q, Xu X, Xie J, Li J, Huang X. Evolution of Computed Tomography Manifestations in Five Patients Who Recovered from Coronavirus Disease 2019 (COVID-19) Pneumonia. Korean J Radiol 2020; 21: 614-619. DOI: $10.3348 / \mathrm{kjr} .2020 .0157$

42. Gross A, Thiemig D, Koch FW, Schwarz M, Gläser S, Albrecht T. CT appearance of severe, laboratory-proven coronavirus disease 2019 (COVID-19) in a Caucasian patient in Berlin, Germany. Rofo 2020; 192 : 476-477. DOI: $10.1055 / \mathrm{a}-1138-8783$

43. Zhu W, Xie K, Lu H, Xu L, Zhou S, Fang S. Initial clinical features of suspected coronavirus disease 2019 in two emergency departments outside of Hubei, China. J Med Virol 2020; 10.1002/jmv.25763. DOI: 10.1002/ jmv.25763.

44. Liu P, Tan XZ. 2019 Novel Coronavirus (2019-nCoV) Pneumonia. Radiology 2020; 295 (1): 19. DOI: 10.1148/radiol.2020200257.

45. Lu T, Pu H. Computed Tomography Manifestations of 5 Cases of the Novel Coronavirus Disease 2019 (COVID-19) Pneumonia From Patients Outside Wuhan. J Thorac Imaging 2020. DOI: 10.1097/ RTI.0000000000000508.

46. Zhu ZW, Tang JJ, Chai XP et al. Comparison of heart failure and 2019 novel coronavirus pneumonia in chest $\mathrm{CT}$ features and clinical characteristics. Zhonghua Xin Xue Guan Bing Za Zhi 2020; 48: E007. DOI: 10.3760/cma.j.cn112148-20200218-00093.

47. Cheng Z, Lu Y, Cao Q et al. Clinical Features and Chest CT Manifestations of Coronavirus Disease 2019 (COVID-19) in a Single-Center Study in Shanghai, China [published online ahead of print, 2020 Mar 14]. Am J Roentgenol 2020; 1-6. DOI: 10.2214/AJR.20.22959.

48. Yoon SH, Lee KH, Kim JY et al. Chest Radiographic and CT Findings of the 2019 Novel Coronavirus Disease (COVID-19): Analysis of Nine Patients Treated in Korea. Korean J Radiol 2020; 21: 494-500. DOI: 10.3348/kjr.2020.0132

49. Xu X, Yu C, Qu J et al. Imaging and clinical features of patients with 2019 novel coronavirus SARS-CoV-2. Eur J Nucl Med Mol Imaging 2020; 47: 1275-1280. DOI: 10.1007/s00259-020-04735-9.

50. Zhao W, Zhong Z, Xie X, Yu Q, Liu J. Relation Between Chest CT Findings and Clinical Conditions of Coronavirus Disease (COVID-19) Pneumonia: A Multicenter Study. Am J Roentgenol 2020; 214: 1072-1077. DOI: 10.2214/AJR.20.22976

51. Wang J, Liu J, Wang Y et al. Dynamic changes of chest CT imaging in patients with corona virus disease-19 (COVID-19). Zhejiang Da Xue Xue Bao Yi Xue Ban 2020; 49 (1). 
52. Zhu Y, Liu YL, Li ZP et al. Clinical and CT imaging features of 2019 novel coronavirus disease (COVID-19). J Infect 2020. DOI:10.1016/j. jinf.2020.02.022.

53. Lin X, Gong Z, Xiao Z, Xiong J, Fan B, Liu J. Novel Coronavirus Pneumonia Outbreak in 2019: Computed Tomographic Findings in Two Cases. Korean J Radiol 2020; 21: 365-368. DOI: 10.3348/kjr.2020.0078.

54. Liu K, Fang YY, Deng $Y$ et al. Clinical characteristics of novel coronavirus cases in tertiary hospitals in Hubei Province. Chin Med J (Engl) 2020; 10.1097/CM9.0000000000000744. DOI: 10.1097/ CM9.0000000000000744.

55. Wu J, Feng CL, Xian XY et al. Novel coronavirus pneumonia (COVID-19) CT distribution and sign features. Zhonghua Jie He He Hu Xi Za Zhi 2020; 43:E030. DOI: 10.3760/cma.j.cn112147-20200217-00106.

56. Pan F, Ye T, Sun P et al. Time Course of Lung Changes On Chest CT During Recovery From 2019 Novel Coronavirus (COVID-19) Pneumonia. Radiology 2020; 200370. DOI: 10.1148/radiol.2020200370.

57. Salehi S, Abedi A, Balakrishnan S, Gholamrezanezhad A. Coronavirus Disease 2019 (COVID-19): A Systematic Review of Imaging Findings in 919 Patients. Am J Roentgenol 2020; 1-7. DOI: 10.2214/AJR.20.23034.

58. Ye Z, Zhang Y, Wang Y, Huang Z, Song B. Chest CT manifestations of new coronavirus disease 2019 (COVID-19): a pictorial review. Eur Radiol 2020; 1-9. DOI: 10.1007/s00330-020-06801-0.

59. Chen N, Zhou M, Dong X et al. Epidemiological and clinical characteristics of 99 cases of 2019 novel coronavirus pneumonia in Wuhan, China: a descriptive study. Lancet 2020; 395: 507-513. DOI: 10.1016/ S0140-6736 (20)30211-7.

60. Pan Y, Guan H, Zhou S et al. Initial CT findings and temporal changes in patients with the novel coronavirus pneumonia (2019-nCoV): a study of 63 patients in Wuhan, China. Eur Radiol 2020; 1-4. DOI: 10.1007/ s00330-020-06731-x.

61. Huang P, Liu T, Huang $L$ et al. Use of Chest $C T$ in Combination with Negative RT-PCR Assay for the 2019 Novel Coronavirus but High Clinical Suspicion. Radiology 2020; 295: 22-23. DOI: 10.1148/radiol.2020200330.

62. Fang Y, Zhang H, Xu Y, Xie J, Pang P, Ji W. CT Manifestations of Two Cases of 2019 Novel Coronavirus (2019-nCoV) Pneumonia. Radiology 2020; 295: 208-209. DOI: 10.1148/radiol.2020200280.

63. Albarello F, Pianura E, Di Stefano F et al. 2019-novel Coronavirus severe adult respiratory distress syndrome in two cases in Italy: An uncommon radiological presentation. Int J Infect Dis 2020; 93: 192-197. DOI: 10.1016/j.ijid.2020.02.043.

64. Wei J, Xu H, Xiong J et al. 2019 Novel Coronavirus (COVID-19) Pneumonia: Serial Computed Tomography Findings. Korean J Radiol 2020; 21: 501-504. DOI: 10.3348/kjr.2020.0112.

65. Hosseiny M, Kooraki S, Gholamrezanezhad A, Reddy S, Myers L. Radiology Perspective of Coronavirus Disease 2019 (COVID-19): Lessons From Severe Acute Respiratory Syndrome and Middle East Respiratory Syndrome. Am J Roentgenol 2020; 214: 1078-1082. DOI: 10.2214/ AJR.20.22969.

66. Kim H. Outbreak of novel coronavirus (COVID-19): What is the role of radiologists? Eur Radiol 2020; 1-2. DOI: 10.1007/s00330-020-06748-2.

67. Guan WJ, Ni ZY, Hu Y et al. Clinical Characteristics of Coronavirus Disease 2019 in China. N Engl J Med 2020; 382: 1708-1720. DOI: 10.1056/NEJMoa2002032.

68. Liu KC, Xu P, Lv WF et al. CT manifestations of coronavirus disease-2019: A retrospective analysis of 73 cases by disease severity. Eur J Radiol 2020; 126: 108941. DOI: 10.1016/j.ejrad.2020.108941.
69. Wu J, Liu J, Zhao $X$ et al. Clinical Characteristics of Imported Cases of COVID-19 in Jiangsu Province: A Multicenter Descriptive Study. Clin Infect Dis 2020; ciaa199. DOI: 10.1093/cid/ciaa199.

70. Bernheim A, Mei X, Huang M et al. Chest CT Findings in Coronavirus Disease-19 (COVID-19): Relationship to Duration of Infection. Radiology 2020; 200463. DOI: 10.1148/radiol.2020200463.

71. Chung M, Bernheim A, Mei X et al. CT Imaging Features of 2019 Novel Coronavirus (2019-nCoV). Radiology 2020; 295: 202-207. DOI: 10.1148/radiol.2020200230.

72. Li W, Cui H, Li K, Fang Y, Li S. Chest computed tomography in children with COVID-19 respiratory infection. Pediatr Radiol 2020; 10.1007/ s00247-020-04656-7. DOI: 10.1007/s00247-020-04656-7.

73. Feng K, Yun YX, Wang XF et al. Analysis of CT Features of 15 Children With 2019 Novel Coronavirus Infection. Zhonghua Er Ke Za Zhi 2020; 58: E007. DOI: 10.3760/cma.j.issn.0578-1310.2020.0007.

74. Xia W, Shao J, Guo Y, Peng X, Li Z, Hu D. Clinical and CT features in pediatric patients with COVID-19 infection: Different points from adults. Pediatr Pulmonol 2020; 55: 1169-1174. DOI: 10.1002/ppul.24718.

75. Kanne JP. Chest CT Findings in 2019 Novel Coronavirus (2019-nCoV) Infections from Wuhan, China: Key Points for the Radiologist. Radiology 2020; 295: 16-17. DOI: 10.1148/radiol.2020200241.

76. Ai T, Yang Z, Hou H et al. Correlation of Chest CT and RTPCR Testing in Coronavirus Disease 2019 (COVID-19) in China: A Report of 1014 Cases. Radiology 2020: 200642.

77. Song F, Shi N, Shan F et al. Emerging 2019 Novel Coronavirus (2019nCoV) Pneumonia. Radiology 2020; 295: 210-217. DOI: 10.1148/radiol.2020200274

78. Li Y, Xia L. Coronavirus Disease 2019 (COVID-19): Role of Chest CT in Diagnosis and Management. Am J Roentgenol 2020; 1-7. DOI: 10.2214/AJR.20.22954.

79. Ai T, Yang Z, Hou $\mathbf{H}$ et al. Correlation of Chest CT and RT-PCR Testing in Coronavirus Disease 2019 (COVID-19) in China: A Report of 1014 Cases. Radiology 2020; 200642. DOI: 10.1148/radiol.2020200642.

80. An P, Song P, Lian K, Wang Y. CT Manifestations of Novel Coronavirus Pneumonia: A Case Report. Balkan Med J 2020; 37: 163-165. DOI: 10.4274/balkanmedj.galenos.2020.2020.2.15.

81. Zu ZY, Jiang MD, Xu PP et al. Coronavirus Disease 2019 (COVID-19): A Perspective from China. Radiology 2020; 200490. DOI: 10.1148/ radiol.2020200490.

82. Xie C, Jiang L, Huang G et al. Comparison of different samples for 2019 novel coronavirus detection by nucleic acid amplification tests. Int J Infect Dis 2020; 93: 264-267. DOI: 10.1016/j.ijid.2020.02.050.

83. Xie X, Zhong Z, Zhao W, Zheng C, Wang F, Liu J. Chest CT for typical 2019-nCoV pneumonia: relationship to negative RT-PCR testing. Radiology 2020:200343. DOI: 10.1148/radiol.2020200343.

84. Xie C, Jiang L, Huang G et al. Comparison of different samples for 2019 novel coronavirus detection by nucleic acid amplification tests. Int J Infect Dis 2020; 93: 264-267. DOI: 10.1016/j.ijid.2020.02.050.

85. Li D, Wang D, Dong $\mathbf{J}$ et al. False-Negative Results of Real-Time Reverse-Transcriptase Polymerase Chain Reaction for Severe Acute Respiratory Syndrome Coronavirus 2: Role of Deep-Learning-Based CT Diagnosis and Insights from Two Cases. Korean J Radiol 2020; 21 (4): 505-508. DOI: $10.3348 / \mathrm{kjr} .2020 .0146$.

Received May 2, 2020. Accepted May 15, 2020. 